\title{
Redistribution of DR4 and DR5 in lipid rafts accounts for the sensitivity to TRAIL in NSCLC cells
}

\author{
WEN OUYANG ${ }^{1}$, CHUNXU YANG $^{1}$, YU LIU ${ }^{1}$, JIE XIONG $^{1}$, JUNHONG ZHANG $^{1}$, YAHUA ZHONG ${ }^{1}$, \\ GONG ZHANG $^{1}$, FUXIANG ZHOU ${ }^{1}$, YUNFENG ZHOU ${ }^{1,2^{*}}$ and CONGHUA XIE ${ }^{1,2^{*}}$ \\ ${ }^{1}$ Department of Radiation and Medical Oncology; ${ }^{2}$ Hubei Key Laboratory of Tumor Biological Behaviors, \\ Zhongnan Hospital, Wuhan University, 169 Donghu Road, Wuchang District, Wuhan 430071, P.R. China
}

Received May 30, 2011; Accepted July 1, 2011

DOI: 10.3892/ijo.2011.1129

\begin{abstract}
The selective toxicity of tumor necrosis factor-related apoptosis-inducing ligand (TRAIL) against tumor cells makes it a potential targeted drug for treating non-small cell lung carcinomas (NSCLC). However, the majority of established human NSCLC cell lines are either partially or completely resistant to TRAIL, resulting in the limitation for clinical use of rhTRAIL and its agonistic antibodies. In this study, compared to TRAIL-sensitive H460 cell line, TRAIL-resistant A549 cell line showed a similar expression level of DR5 and a higer expression level of DR4. It indicates that there is no positive correlation between the expression levels of death receptors and sensitivity to TRAIL. However, tests on A549 cells with DR4 siRNA transfection revealed that DR4-competitive binding to TRAIL could not affect the capacity of TRAIL in inducing apoptosis. Instead, further studies found that the aggregation of DR4 and DR5 in lipid rafts only occured in $\mathrm{H} 460$ cells with TRAIL pretreatment. It suggested that the TRAIL-induced redistribution of DR4 and DR5 in lipid rafts contributed to the sensitivity to TRAIL in TRAIL-sensitive NSCLC H460 cell line, which was also confirmed by intervention tests of the cholesterol-sequestering agent nystatin.
\end{abstract}

Correspondence to: Dr Conghua Xie, Department of Radiation and Medical Oncology, Zhongnan Hospital, Wuhan University, 169 Donghu Road, Wuchang District, Wuhan 430071, P.R. China

E-mail: chxie_65@hotmail.com

*Contributed equally

Abbreviations: TRAIL, tumor necrosis factor-related apoptosisinducing ligand; NSCLC, non-small cell lung carcinomas; DR4, death receptor 4; DR5, death receptor 5; DISC, death-induced signaling complex; FADD, Fas-associated death domain; FLIP, FLICE inhibitory protein; FITC, fluorescein; PE, phycoerythrin; HRP, horseradish peroxidase; SFM, serum-free medium

Key words: TRAIL, sensitivity, death receptor, redistribution, lipid rafts

\section{Introduction}

Lung cancer is the leading cause of cancer death for both men and women over the world, and non-small cell lung carcinomas (NSCLC) constitute $75 \%$ of lung cancer. Although recent advances in the chemotherapeutic management of NSCLC have improved its prognosis, no curative therapy currently exists for advanced lung cancer patients. Accordingly, new therapeutic methods need to be developed. Targeted molecular therapy applied to lung cancer has rapidly developed in recent years. Due to its preferential inducibility of apoptosis in cancer cells over normal cells $(1,2)$, tumor necrosis factor-related apoptosis-inducing ligand (TRAIL) is a promising targeted therapy drug (3-5). It is reported that TRAIL can induce apoptosis in NSCLC cell lines (6) and inhibit the growth of NSCLC xenografts (2). However, the majority of human NSCLC cells are resistant to TRAIL. Instead of benefiting from TRAIL treatments, patients with TRAIL-resistant tumor may probably suffer from the potential side-effects. Consequently, resistance of NSCLC cells to TRAIL-induced apoptosis is a limitation for the clinical use of both rhTRAIL and its agonistic antibodies, so it is very important to investigate the molecular mechanisms of TRAIL-resistance in NSCLC cells and to find the therapeutic agents that could switch TRAIL signals from cell survival to cell death.

TRAIL is a member of the tumor necrosis factor (TNF) family $(7,8)$ and plays a role in tumor immunosurveillance (9). It induces apoptosis in a variety of cancer cells $(7,10)$ by interacting with its death receptors DR4 (TRAIL-R1) (11) and DR5 (TRAIL-R2) (12) on target cell surface. DR4 and DR5 contains a cytoplasmic region designated as the death domain, which is responsible for transducing the death signal. On ligand binding, DR4 or DR5 initiates apoptosis by assembly of death-induced signaling complex (DISC) components at the inner surface of plasma membrane (13), such as the adaptor protein Fas-associated death domain (FADD) and the apoptosis initiating protease pro-caspase-8 (or pro-caspase-10). Within the DISC, pro-caspase- 8 or pro-caspase-10 is autocatalytically cleaved and releases active caspase- 8 or caspase-10 into the cytoplasm, subsequent cleaving and activating effector caspases, such as caspase- 3 , caspase- 6 and caspase- 7 in the extrinsic apoptotic pathway. At the same time, caspase- 8 stimulates the cleavage of Bid, thus amplifying caspase activa- 
tion through mitochondria activating the intrinsic apoptotic pathway (14). The apoptotic machinery is shared by both TRAIL and its agonistic antibody against DR4 or DR5.

TRAIL-resistance in cancer cells is caused by many reasons. In some cases, it is caused by the simultaneous expression of decoy receptors (DcR1, DcR2 and OPG) which lack a death domain but possess a comparable binding affinity to TRAIL. However, the presence of decoy receptors can not explain the lack of response of cancer cells to antibodies specifically targeting DR4 or DR5 (3,15-17). Other defects along the apoptotic pathway, including downregulation of caspase- 8 or caspase-10, overexpression of antiapoptotic molecules, such as cellular FLICE inhibitory protein (FLIP), Bcl-2, Akt and others (4) are involved in TRAIL resistance in several cell lines. However, none of these factors showed a consistent correlation with TRAIL resistance in multiple cancer cells (18).

TRAIL binding to its death receptors is an upstream event during caspase activation, so the effects of receptors is crucial in initialing apoptosis. However, there seems to be no evidence to confirm the direct correlation between total expression level of any receptor and the sensitivity of cancer cells to TRAIL, which was also comfirmed in our study. Previous studies suggested that the mRNA and protein expression of death receptors did not reflect their functional protein levels due to post-translational regulation. It was reported that $\mathrm{O}$-glycosylation of death receptors correlated with TRAIL sensitivity in pancreatic carcinoma, nonsmall cell lung carcinoma and melanoma cell lines. However, it was only detected in a small portion of cancers (18). Moreover, other studies indicated the functional status of death receptors correlated with the death receptor expression levels on cell surface in some colon cancer cells (19) and leukemia cells (20). Thus, some interventions are able to upregulate cancer cells sensitivity to TRAIL by elevating the cell surface expression of death receptors, which was also comfirmed in SW480 and Hep-2R cell line in our previous study $(21,22)$.

It is reported that lipid rafts serve as plasma membrane platforms for death receptor redistribution and death receptorinitiated signals (23-25). Lipid rafts are rich in cholesterol and sphingolipid fractions of the plasma membrane (26). Several studies reported that the distribution of receptors in lipid rafts is related to the sensitivity of respective ligand (27). Other reports indicated drugs or interventions which are capable of interfering with lipid rafts could influence TRAIL receptor distribution in the plasma membrane, and finally lead to affect sensitivity to TRAIL (28). However, little is known about the correlation between death receptor distribution in lipid rafts and TRAIL-sensitivity in lung cancer cells. Our study showed that the expression and the original distribution of death receptors on cell surface was not related to sensitivity of NSCLC cells to TRAIL, and nystatin, a cholesterol-sequestering agent, (28) downregulated H460 cell TRAIL-induced apotosis by restraining death receptors TRAIL-induced redistribution into lipid rafts. In other words, nystatin could not affect the initial distribution of DR4 and DR5 on membrane surface, but could prevent DR4 and DR5 from migrating into lipid rafts. Our results show that it is the redistribution induced by TRAIL, not initial distribution of DR4 and DR5 in lipid rafts of membrane surface, that contributed to the sensitivity to TRAIL-induced apoptosis in two NSCLC cell lines.

\section{Materials and methods}

Cell culture and transfection. Human NSCLC cell lines including A549 and NCI-H460 (H460) were obtained from the Type Culture Collection of the Chinese Academy of Sciences (Shanghai, China). Both cell lines were cultured in RPMI-1640 medium (Hyclone, USA) at $37^{\circ} \mathrm{C}$ in a humidified atmosphere of $5 \% \mathrm{CO}_{2}$. The media were supplemented with $10 \%$ heat-inactivated fetal bovine serum and $1 \%$ penicillin/streptomycin and were changed every 3-5 days. For transfection, cells were seeded into six-well plates $\left(5 \times 10^{5}\right.$ cells/well) without antibiotics. After $24 \mathrm{~h}$, cells were transfected with DR4 siRNA (Santa Cruz, USA) using Lipofectamine 2000 reagent (Invitrogen, USA) according to the manufacturer's instructions. DR4 siRNA (4 $\mu \mathrm{l})$ was mixed with $100 \mu \mathrm{l}$ of serum-free medium (SFM), then $3 \mu \mathrm{l}$ of Lipofectamine 2000 mixed with $150 \mu \mathrm{l}$ of SFM was added, and incubated for $20 \mathrm{~min}$ at room temperature. Finally, the resultant mixture was added to cells in each well. The medium was replaced with medium containing fresh serum $5 \mathrm{~h}$ after transfection.

Antibodies and reagents. rhTRAIL, designed for clinical use, was obtained from Shanghai TRAIL Bio-technical Co., Ltd. Monoclonal antibodies specific to the extracellular domains of human death receptors DR4 and DR5 and caveolin-1, GAPDH were purchased from Santa Cruz Biotechnology Inc. Antibody to procaspase-8 was from Bioworld Technology Inc. Fluorescein (FITC)-conjugated monoclonal anti-TRAIL antibody was from Abcam (Cambridge, MA). FITC-conjugated goat anti-human DR4 and phycoerythrin (PE)-conjugated goat anti-human DR5 mouse IgG was from Beijing Boisynthesis Biotechnology Co., Ltd. Horseradish peroxidase (HRP)conjugated goat anti-mouse $\mathrm{IgG}$ and goat anti-rabbit IgG were from Southern Biotech. Protease inhibitor mixture, Triton X-100, Tween-20 and other chemicals of analytic grade were purchased from Sigma-Aldrich.

MTT cell proliferation assay. TRAIL-sensitivity of A549 and H460 cell lines respectively, was detected by MTT assay. Cells were cultured at $2 \times 10^{5} / \mathrm{ml}$ in $100 \mu \mathrm{l}$ aliquots in 96-well tissue culture plates (Corning, USA). A blank control group (nutritive medium only), a negative control group (untreated cells), TRAIL-treated groups (cells treated with indicated concentrations of rhTRAIL) were designed for this experiment. Briefly, A549 or H460 cells were seeded into 96-well plates for $24 \mathrm{~h}$, indicated concentrations of TRAIL $(0,0.05,0.1,0.5,1,5,10$, $50,100,500,1000 \mathrm{ng} / \mathrm{ml})$ was then added to the respective well. After incubation at $37^{\circ} \mathrm{C}$ for $16 \mathrm{~h}, 10 \mu \mathrm{l}$ MTT was added to $50 \mu \mathrm{l}$ solution each well $(5 \mathrm{mg} / \mathrm{ml}$ final concentration). The plates were incubated at $37^{\circ} \mathrm{C}$ for an additional $4 \mathrm{~h}$ to allow MTT to form formazan crystals by reacting with metabolically active cells. The formazan crystals were solubilized in $100 \mu \mathrm{l}$ indicated dissolving agent at $37^{\circ} \mathrm{C}$ for $4 \mathrm{~h}$. The absorbance values of the solution in each well were measured at $490 \mathrm{~nm}$ using a microplate reader (Beckman, USA). Cell viability was determined by the formula: cell viability $(\%)=($ absorbance of the treated wells - absorbance of the blank control wells)/ (absorbance of the negative control wells - absorbance of the blank control wells) x100\%. All MTT experiments were performed in five replicates and repeated at least three times. 
Apoptosis assays. Cells were grown on 6-well plates to 70-80\% confluence and treated with indicated concentrations of rhTRAIL or DR4 siRNA transfection or both of the above treatments, or non-treatment. At first, cells were pretreated with the caspase inhibitor ZVAD-fmk for $2 \mathrm{~h}$ in order to block endogenous TRAIL-induced apoptosis, then at the selected time points, cells were harvested by trypsinisation, and washed with ice-cold PBS three times (Hyclone, USA) and resuspended in $400 \mu \mathrm{l}$ binding buffer (Bestbio, China), stained with $5 \mu$ l Annexin-V-FTIC (Bestbio) for $15 \mathrm{~min}$, then $10 \mu \mathrm{l}$ of $20 \mu \mathrm{g} / \mathrm{ml}$ propidium iodide (Bestbio) for $5 \mathrm{~min}$ in the dark at room temperature. Finally, cell apoptotic profile was analysed immediately in flow cytometer (Beckman). The percentage of apoptotic cells was obtained from a bivariate histogram of Annexin-V-FTIC labeled-cells versus propidium iodide-labeled DNA.

Flow cytometric analysis of death receptors of cell surface expression and of binding to TRAIL. Procedure for cell surface expression of death receptors DR4 and DR5, followed the manufacturer's recommendations. In brief, cells at 70-80\% confluence were pretreated with $50 \mathrm{ng} / \mathrm{ml}$ TRAIL for $20 \mathrm{~min}$ or non-treated, then cells were harvested by trypsinisation and washed twice in ice-cold PBS. Cells $\left(2 \times 10^{5}\right)$ were incubated in $40 \mu \mathrm{l}$ PBS containing $1 \%$ goat serum for $40 \mathrm{~min}$ at room temperature. After washing with PBS three times, cells were incubated with anti-DR4 or anti-DR5 mouse antibody (dilution ratio is $1: 30$ ) overnight at $4^{\circ} \mathrm{C}$. Afterwards, cells were washed again three times with PBS, and incubated with FITC/ $\mathrm{PE}$-conjugated goat anti mouse $\operatorname{IgG}$ (dilution ratio is 1:50) for $40 \mathrm{~min}$ in dark at room temperature. Finally, cells were washed three times with PBS and resuspended in $0.5 \mathrm{ml}$ PBS for flow cytometry analysis.

The analysis of death receptor binding to TRAIL was performed as described (29) with modifications. Briefly, $1 \times 10^{6}$ cells were suspended in $100 \mu \mathrm{l}$ of complete growth medium and incubated with or without rhTRAIL $(50 \mathrm{ng} / \mathrm{ml})$ on ice for $30 \mathrm{~min}$ and then with FITC-conjugated anti-TRAIL antibody $(10 \mu \mathrm{g} / \mathrm{ml})$ for an additional $30 \mathrm{~min}$. Formation of TRAIL immunocomplexes was initiated by increasing temperature to $37^{\circ} \mathrm{C}$ for the indicated times (5-60 min), and terminated by adding ice-cold PBS. Cells were then washed three times with PBS and resuspended in cold PBS immediately for flow cytometry analysis.

Reverse transcription-PCR. Total RNA was isolated from different cells using TRIzol reagent (Invitrogen). RT-PCR was carried out using High-Fidelity RT-PCR kit (Invitrogen) as per the manufacturer's instructions. Primer pairs used for detection of DR4 are 5'-agagagaagtccetgcacca-3' and 5'-gtcactccagggcgta caat-3' $\left(\mathrm{Tm}, 57^{\circ} \mathrm{C}\right)$, primer pairs for DR5 are $5^{\prime}$-caccaggtgtgatt caggtg- $3^{\prime}$ and $5^{\prime}$-ccccactgtgc tttgtacct- $3^{\prime}\left(\mathrm{Tm}, 57^{\circ} \mathrm{C}\right)$, primer pairs for GAPDH are 5'-tggaaggactcatgaccaca-3' and 5'-ttcag ctcagggatgacctt-3 $\left(\mathrm{Tm}, 56^{\circ} \mathrm{C}\right)$. Amplification products were electrophoresed on $2 \%$ agarose gels containing ethidium bromide for visualization under UV light. All PCR reactions were performed at least three times. GAPDH was used to normalize mRNA levels.

Western blotting. Levels of caspase-8, DR4, DR5 and caveolin-1 were determined by Western blotting in cell extracts.
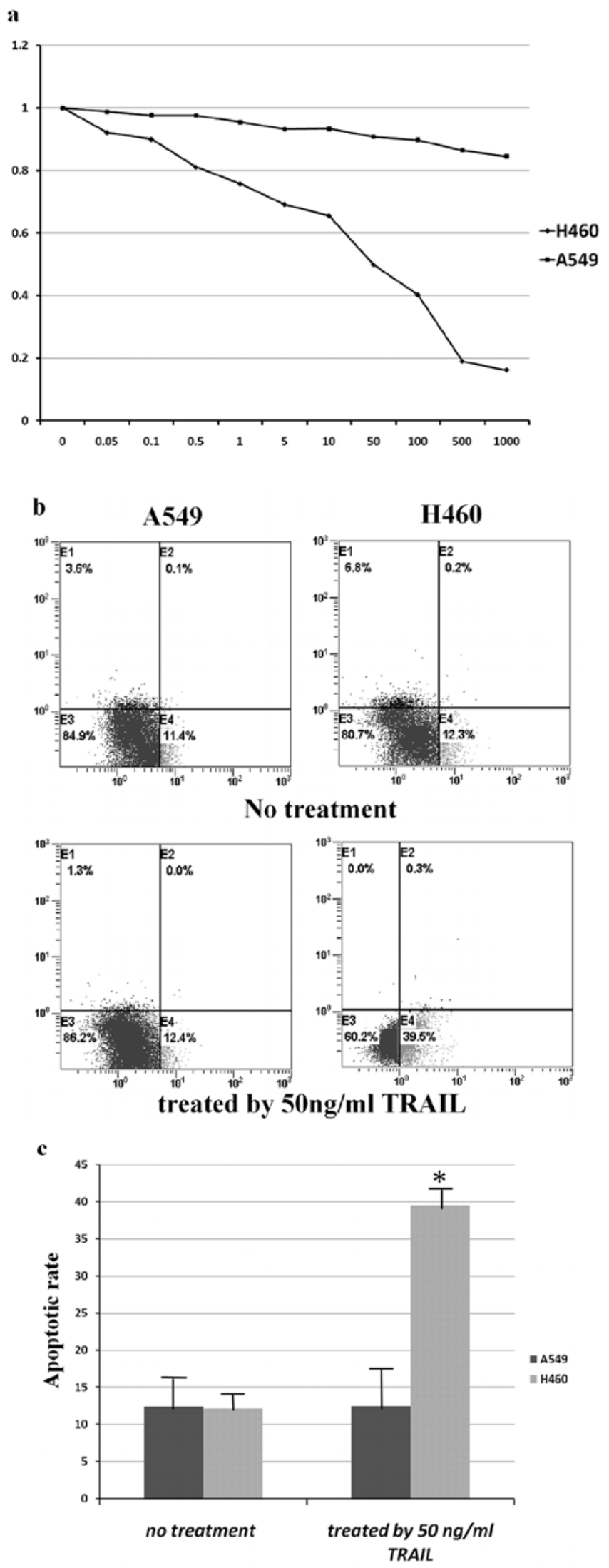

Figure 1. TRAIL-sensitivity of two NSCLC cells in vitro. (a) A549/H460 cells exposed to medium containing TRAIL from 0 to $1000 \mathrm{ng} / \mathrm{ml}$ for $24 \mathrm{~h}$ were tested by MTT assay to determine inhibitory rates. The result was shown as line graph (mean); (b) A549/ H460 cells exposed to medium containing the 0 or $1000 \mathrm{ng} / \mathrm{ml}$ TRAIL for $16 \mathrm{~h}$ were analyzed by flow cytometry after staining with Annexin V-FITC and propidium iodide for apoptosis; (c) A graphical representation of the mean data presented in (b). ${ }^{*} \mathrm{P}<0.05$ compared with control. Columns represent mean data. 

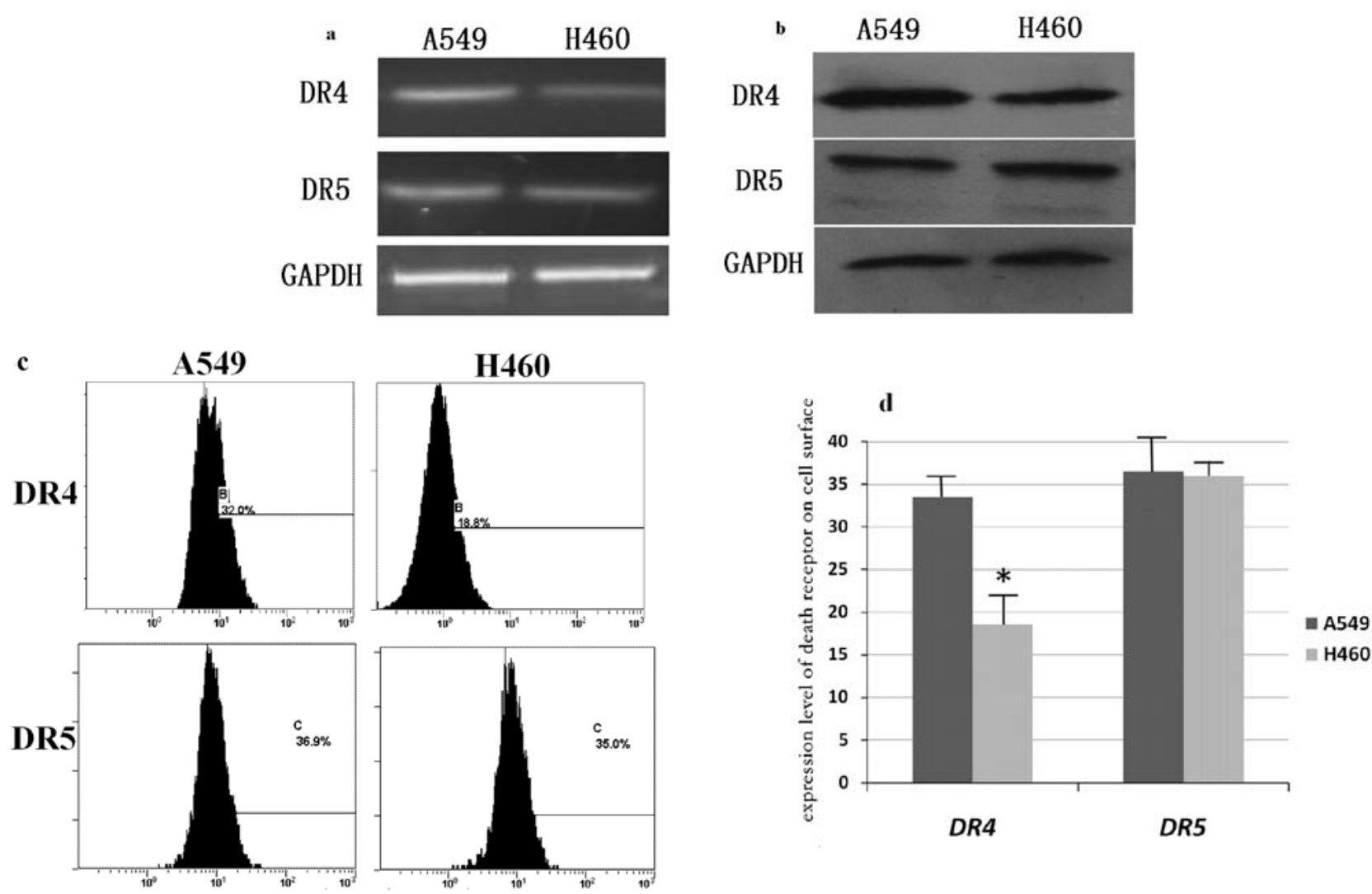

Figure 2. The death receptor expression levels of TRAIL-sensitive H460 cell and TRAIL-resistant A549 cells. (a) The mRNA expressions of DR4/DR5 in A549 and H460 cell were detected by RT-PCR; (b) The protein expressions of DR4/DR5 in A549 and H460 cells were detected by Western blotting. The mRNA/protein expression of DR4/DR5 was normalized by GAPDH; (c) The cell surface DR4/DR5 expressions of A549 and H460 cells without any treatment was detected by flow cytometry; (d) A graphic representation of the mean data presented in (c). "P<0.05 compared to control. Columns represent the mean data.

Cells were washed three times with ice-cold PBS, exposed to recommended volume RIPA lysis buffer (Biyuntian, Shanghai). After centrifugation at $12,000 \mathrm{rpm}$ for $5 \mathrm{~min}$ at $4^{\circ} \mathrm{C}$, the supernatants were removed and diluted in $5 \mathrm{X}$ loading buffer (Biyuntian). Samples (30 $\mu \mathrm{g}$ of whole-cell lysates per lane) were separated by 10-12\% SDS-PAGE electrophoresis under denaturing conditions, then transferred to PVDF membranes (Biyuntian). After $1 \mathrm{~h}$ block with 5\% non-fat milk in TBST (TBS with 0.1\% Tween-20) at room tempreture, the membrane was incubated overnight with the primary antibodies at $4^{\circ} \mathrm{C}$, washed three times with TBST, incubated for $60 \mathrm{~min}$ at room temperature with HRP-conjugated goat anti-mouse or anti-rabbit antibodies, then washed three times with TBST again. Finally, immunoreactive protein was detected with an enhanced chemiluminescence detection kit (Biyuntian). GAPDH was used to normalize protein levels.

Lipid raft and non-raft fractionation and protein analyses. Lipid raft and non-raft soluble fractions were separated by discontinuous sucrose density gradients of Triton X-100 cell lysates from treated and untreated cells. In brief, cells from 10 bottles of $15-\mathrm{cm}$ culture dishes $\left(1 \times 10^{8}\right.$ cells) were homogenized on ice for $30 \mathrm{~min}$ in $1 \mathrm{ml}$ of MNX buffer (1\% Triton X-100 in $25 \mathrm{mmol} / \mathrm{l} \mathrm{MES}, 150 \mathrm{mmol} / \mathrm{l} \mathrm{NaCl}, \mathrm{pH}$ 6.5) supplemented with $1 \mathrm{mmol} / \mathrm{l}$ of phenylmethylsulfonyl fluoride and protease inhibitor cocktail (Sigma). The homogenates were mixed with
$1 \mathrm{ml}$ of $80 \%$ sucrose made with MNX buffer and placed on the bottom of a centrifuge tube. The samples were then overlaid with $3.5 \mathrm{ml}$ of $35 \%$ sucrose and $3.5 \mathrm{ml}$ of $5 \%$ sucrose and centrifuged at $175,000 \times \mathrm{g}$ (Beckman) for $20 \mathrm{~h}$ at $4^{\circ} \mathrm{C}$. Nine fractions of $1 \mathrm{ml}$ were collected from the top to the bottom of the gradient and analyzed. To identify lipid raft fractions, the fractions were examined by Western blotting with antibodies to the lipid raft markers caveolin-1 (25). The protein in each fraction was analyzed by Western blotting.

\section{Results}

Sensitivity to TRAIL of two NSCLC cell lines in vitro. TRAIL has been shown to induce apoptosis in TRAIL-sensitive NSCLC cell lines and inhibit the growth of the xenografts generated from the cell lines $(2,6,30)$. However, it is reported that the majority of the NSCLC cell lines were either partially or completely resistant to TRAIL treatment (27). We evaluated the sensitivity of two NSCLC cell lines to rhTRAIL in MTT assay and flow cytometric apotosis. The MTT assay confirmed that $\mathrm{H} 460$ (IC50 $=50 \mathrm{ng} / \mathrm{ml}$ ) was TRAIL sensitive, whereas A549 was TRAIL resistant (Fig. 1a). The respective apoptosis rate of the two cell types showed similar trend (Fig. $1 \mathrm{~b}$ and c), and results also indicated that TRAIL inhibited cell proliferation in sensitive cells in the way of apoptosis induction, as determined by Annexin V-PI binding. 


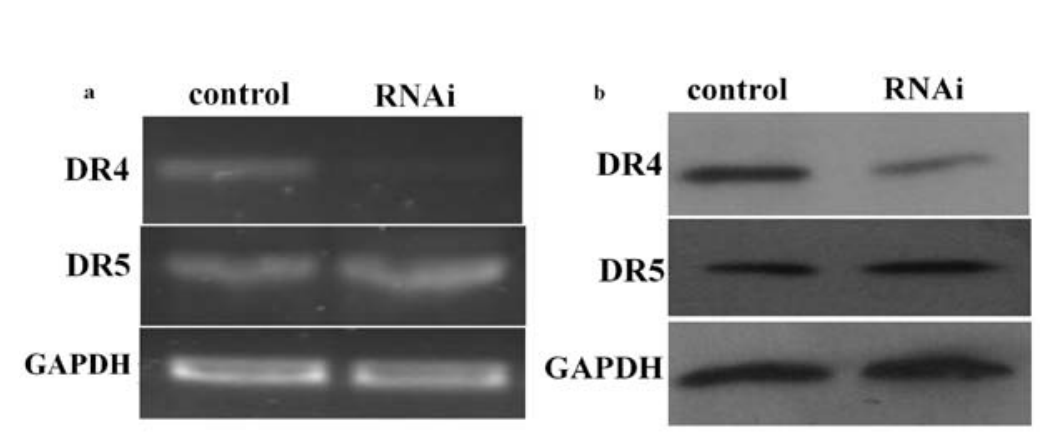

d
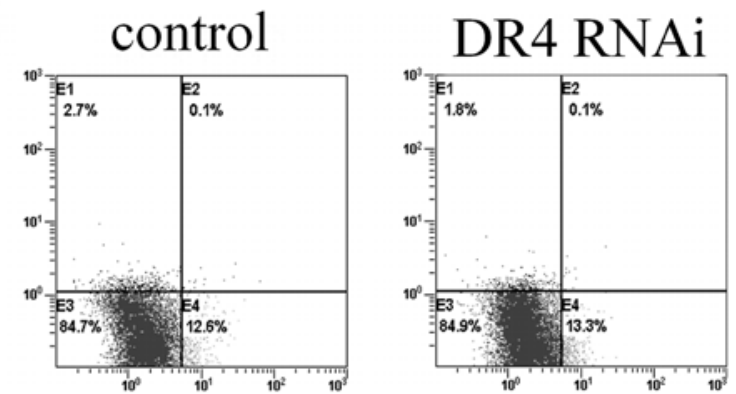

no treatment
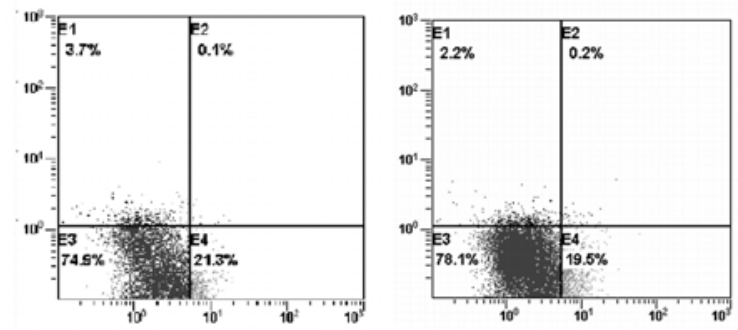

treated by $1000 \mathrm{ng} / \mathrm{ml}$ TRAIL for $16 \mathrm{~h}$
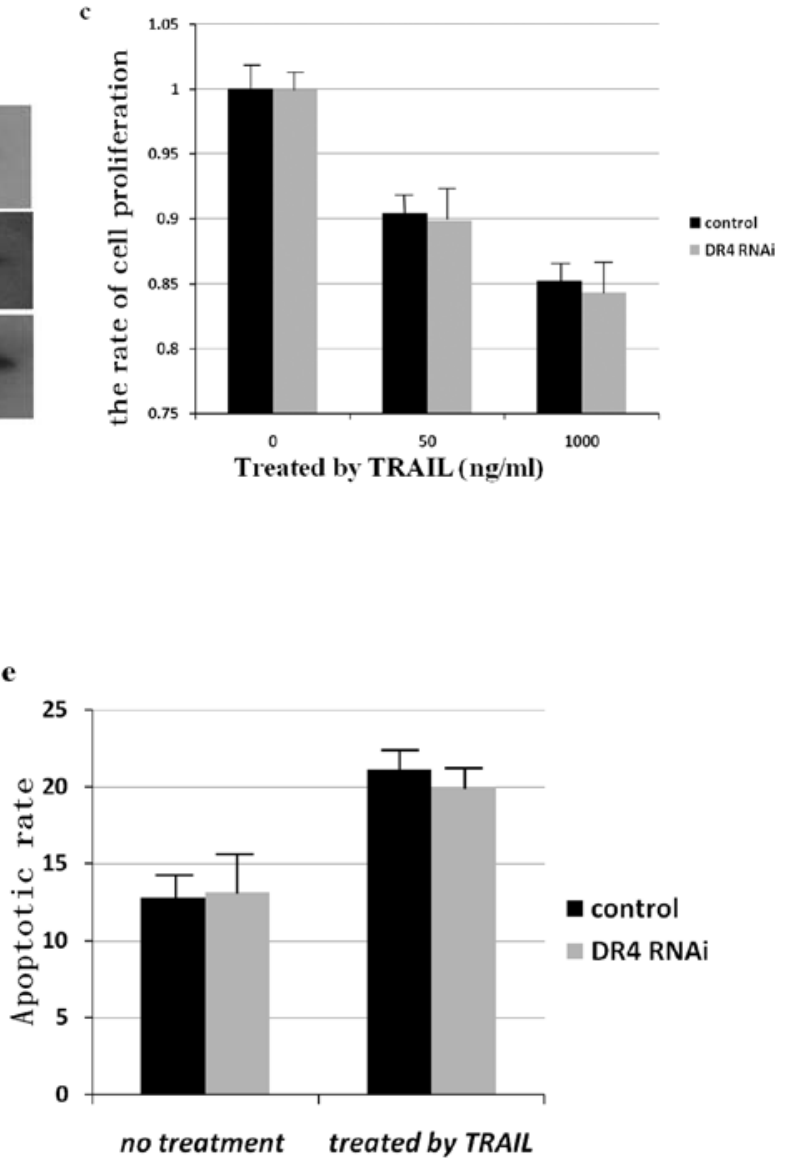

Figure 3. The inhibitory and apoptotic rates of A549 cells with or without DR4 gene silencing. (a) The mRNA expression of DR4/DR5 in A549 cells with or without DR4 gene silencing was examined by RT-PCR; (b) The protein expression of DR4/DR5 in A549 cell with or without DR4 gene silencing was examined by Western blotting. The mRNA/protein expression of DR4/DR5 was normalized by GAPDH. (c) The inhibitory rates of A549 cells with or without DR4 gene silencing after TRAIL treatment at indicated concentration for $16 \mathrm{~h}$, which were tested by MTT assay; (d) The apoptotic rates of A549 cells with or without DR4 gene silencing were analyzed by flow cytometry after 0 or $1000 \mathrm{ng} / \mathrm{ml}$ TRAIL treatment for $16 \mathrm{~h}$; (e) A graphic representation of the mean data presented in (d). ${ }^{*} \mathrm{P}<0.05$ compared to control. Columns represent mean data.

TRAIL-sensitive H460 and TRAIL-resistant A549 cells show differential death receptors expression levels. The expression of DR4 and DR5 was evaluated by RT-PCR (Fig. 2a) and Western blotting (Fig. 2b). TRAIL-sensitive H460 and TRAILresistant A549 cells express a similar level of DR5 in both mRNA and protein, whereas A549 cells have a higher expression level of DR4 than H460 cell. Flow cytometric analysis of the expression of DR4 and DR5 on plasma membrane showed similar trend (Fig. 2c and d). The above results revealed that there is no positive correlation between the expression levels of its respective death receptors and sensitivity to TRAIL. On the contrary, TRAIL-resistant A549 cells express more DR4. According to recent findings that DR5 is the major receptor that transduces the death signal, we hypothesize that more DR4 competing with DR5 in binding to TRAIL resulted in TRAIL-resistance of the A549 cell line.

DR4 gene silencing of A549 cells did not affect the capacity of TRAIL in inducing apoptosis. In order to investigate the effect of DR4 competitive binding to TRAIL in A549 cell line, we examined whether DR4 gene silencing could elevate A549 cell sensitivity to TRAIL. Under DR4 siRNA transfection, the expression of DR4 was restrained and DR5 had no change, which was confirmed by RT-PCR (Fig. 3a) and Western blotting (Fig. 3b), but there was almost no change in the cell proliferation (Fig. 3c) and apoptosis (Fig. 3d and e) induced by TRAIL. That is contrary to our hypothesis. The results indicated DR4 competitive binding to TRAIL did not affect the capacity of TRAIL in inducing apoptosis of A549 cells. There appear to be other mechanisms of TRAIL-resistance in A549 cell line.

TRAIL induces cell surface death receptor accumulation in plasma membrane. The effects of receptors appear to be upstream events during apoptosis initiation, and only cell membrane surface DR4 and DR5 are able to bind with TRAIL and transduce the apoptotic signal, so we examined the cell surface expression levels of TRAIL death receptors using FITC/PE-conjugated antibodies by flow cytometry. Similar to mRNA and protein expression, A549 cells showed a higher cell surface expression level of DR4 but equal DR5 to 
H460 cells without any treatments (Fig. 2c and d). However, after $50 \mathrm{ng} / \mathrm{ml}$ TRAIL treatment for $20 \mathrm{~min}$, both A549 and H460 cells showed a significant reduction of DR4 and DR5 on the cell membrane surface (Fig. 4a and b). It seemed that TRAIL downregulated surface expression of DR4 and DR5 in both NSCLC cell lines. However, further detection of the expression of total mRNA and protein showed that both A549 and H460 cell lines with treatment of TRAIL is the same as without treatment (data not shown).

We further detected the amount of death receptors binding to ligand after TRAIL pretreatment. The two different TRAIL-sensitive cell lines had almost equal formation of TRAIL immunocomplexes at the first $5 \mathrm{~min}$, and H460 cells showed an elevated formation in a time-dependent manner (Fig. 4c). However, the formation in A549 cells was very slight (Fig. 4c). The formation of TRAIL immunocomplexes indirectly reflect the amount of death receptors distributed on cell surface and binding to TRAIL. For this reason, under TRAIL pretreatment, the different status of TRAIL uptake and death receptor migration on cell surface correlates with the A549 and H460 cell respective TRAIL-sensitivity, but it seems to conflict with the change of DR4 and DR5 cell surface expression levels, which were directly detected by specific antibody against the respective death receptor (Fig. 4a and b). The possible explanation is that DR4 and DR5 would be unavailable to its respective primary antibody after TRAIL pretreatment. The results suggest that DR4 and DR5 only on cell membrane surface are capable of binding to TRAIL and transduction of apoptotic signal, and TRAIL-sensitive lung cells show more death receptor aggregates on the membrane surface than TRAIL-resistant lung cells.

TRAIL promoted DR4 and DR5 to aggregate into lipid rafts. Recent studies indicated the role of lipid rafts in the initiation of death receptor-induced apotosis. It led us to investigate whether TRAIL induce death receptor redistribution in lipid rafts involved in TRAIL-sensitivity. In our study, caveolin-1, as the maker of lipid rafts (25) were detected in fractions 4 and 5 (Fig. 5a and b). Without TRAIL pretreatment, in NSCLC cells DR4 and DR5 were detected in both the lipid raft and non-raft fractions, whereas caspase- 8 was found in non-raft fractions (Fig. 5a and b). The results suggested no correlation between DR4 or DR5 initial distribution in lipid rafts and TRAIL sensitivity of the cell lines without treatment. It is noteworthy that the H460 cells pretreated by TRAIL showed redistribution of DR4, DR5 and caspase-8 from the non-raft into the lipid raft fractions (Fig. 5b), which did not occur in A549 cells. It suggested that the TRAIL-induced redistribution of DR4 and DR5 in lipid rafts contributed to the sensitivity to TRAIL in the H460 cell line, and the migration of caspase- 8 may be related to the formation of DISC.

In order to confirm the above results, we further examined the status of DR4, DR5 and caspase- 8 redistribution and apotosis of $\mathrm{H} 460$ with nystatin intervention. At $20 \mathrm{ng} / \mathrm{ml}$ nystatin for the last $12 \mathrm{~h}$, nystatin could not affect the initial distribution of DR4 and DR5 on membrane surface, and after TRAIL pretreatment, DR4, DR5 and caspase-8 in H460 cells still could not migrate into lipid rafts (Fig. 5c). As a result, the nystatin treatment significantly downregulated the TRAILinduced apotosis of $\mathrm{H} 460$ cell (Fig. $5 \mathrm{~d}$ and e). The results a
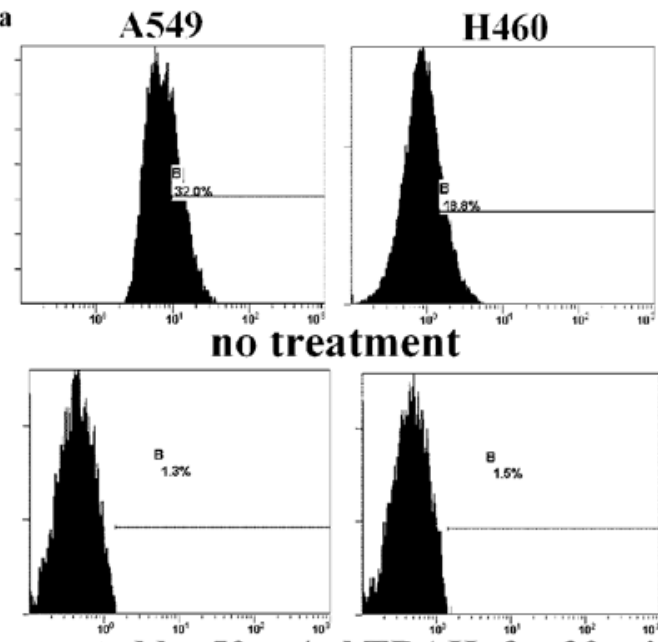

treated by $50 \mathrm{ng} / \mathrm{ml}$ TRÂIL for $20 \mathrm{~min}$

b
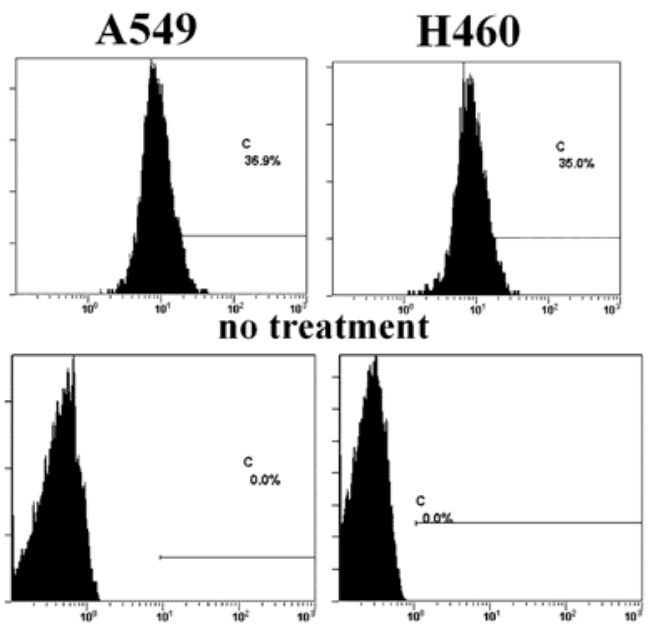

treated by $50 \mathrm{ng} / \mathrm{ml}$ TRAIL for $20 \mathrm{~min}$
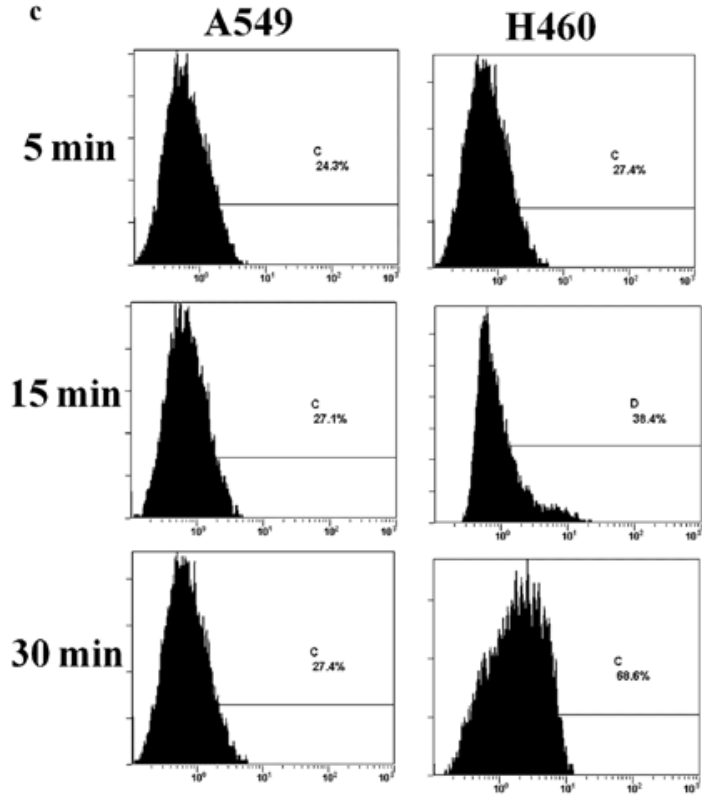

Figure 4. The cell surface death receptor expression levels of A549 and H460 cells with or without TRAIL pretreatment. (a) The cell surface expression level of DR4 on A549/H460 cells with or without $50 \mathrm{ng} / \mathrm{ml}$ TRAIL pretreatment was analyzed by flow cytometry; (b) The cell surface expression of DR5 on A549/ H460 cells with or without $50 \mathrm{ng} / \mathrm{ml}$ TRAIL pretreatment was analyzed; (c) The amount of TRAIL binding to death receptors on the cell surface of A549/H460 cells was treated by $50 \mathrm{ng} / \mathrm{ml}$ TRAIL for indicated time, which indirectly reflects the amount of death receptors on the cell surface. 
a
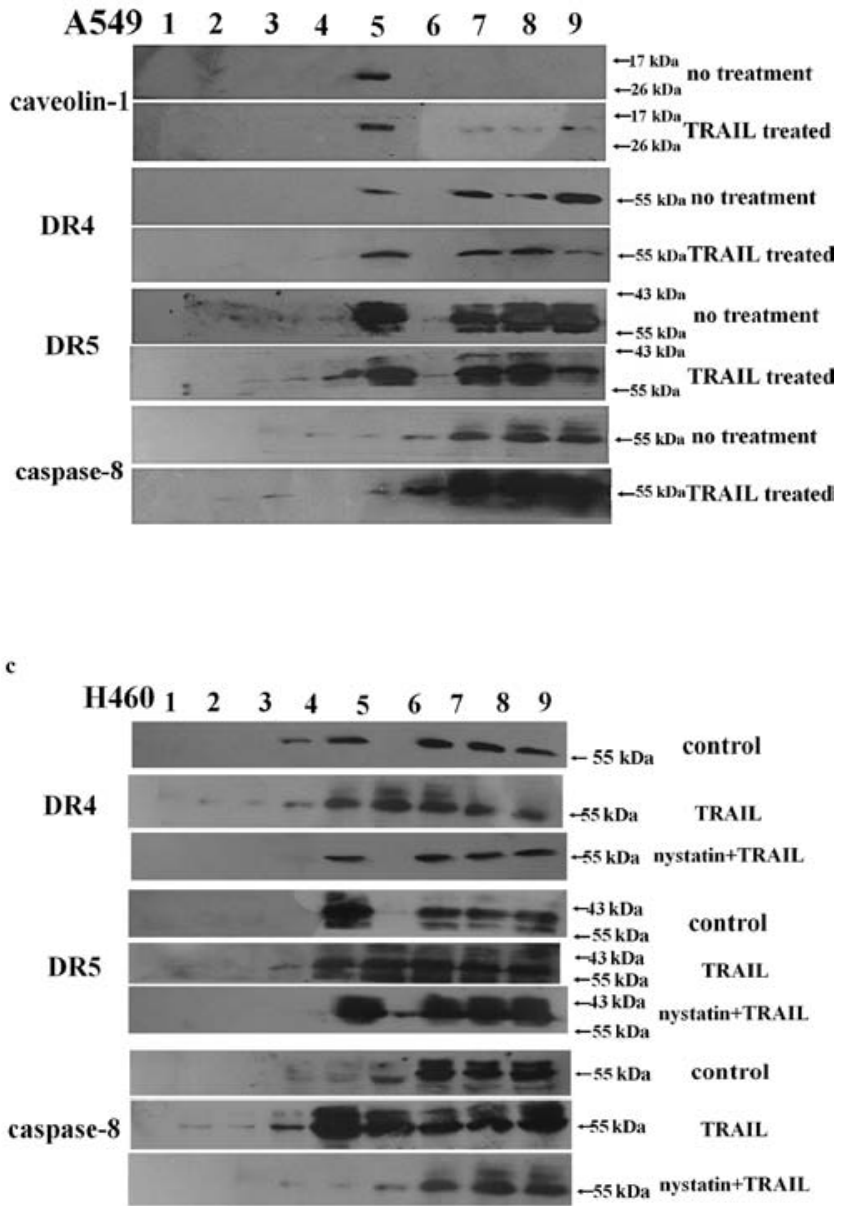

b
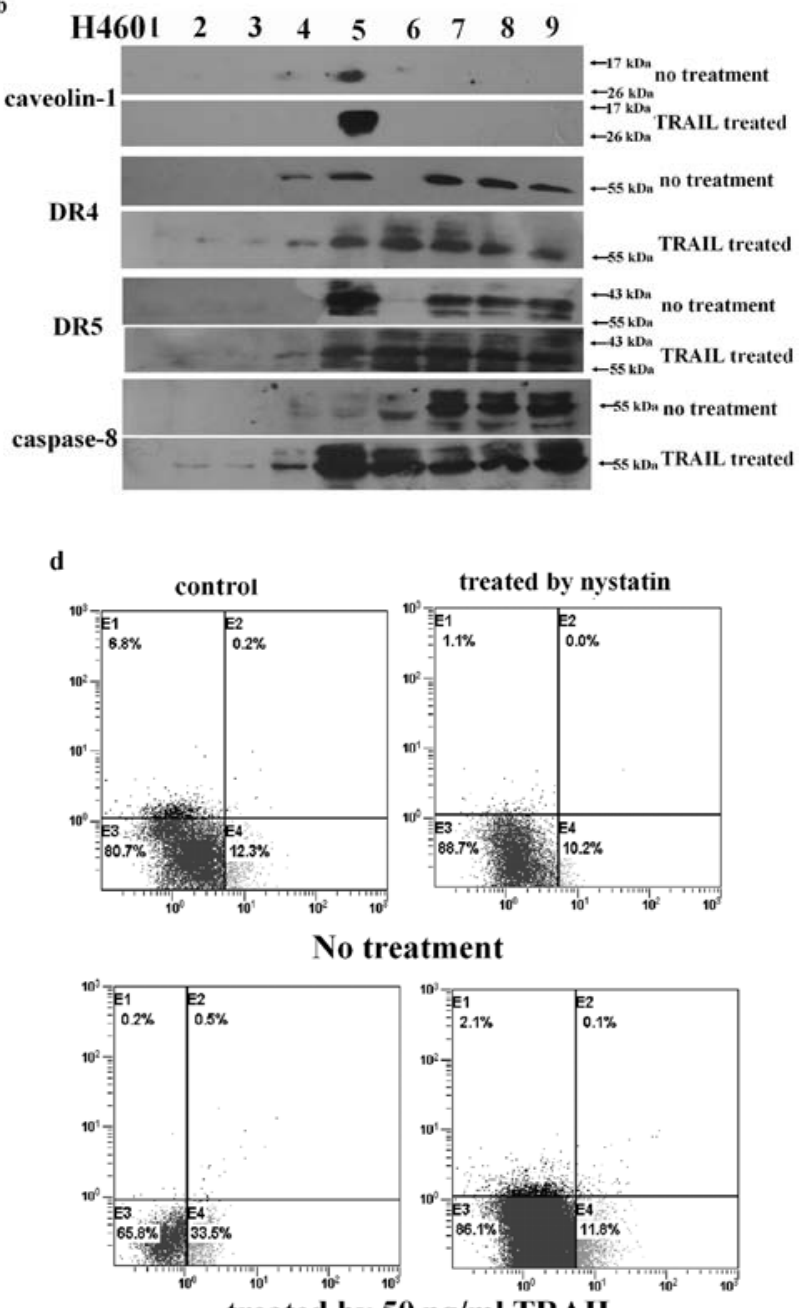

treated by $50 \mathrm{ng} / \mathrm{ml}$ TRAIL

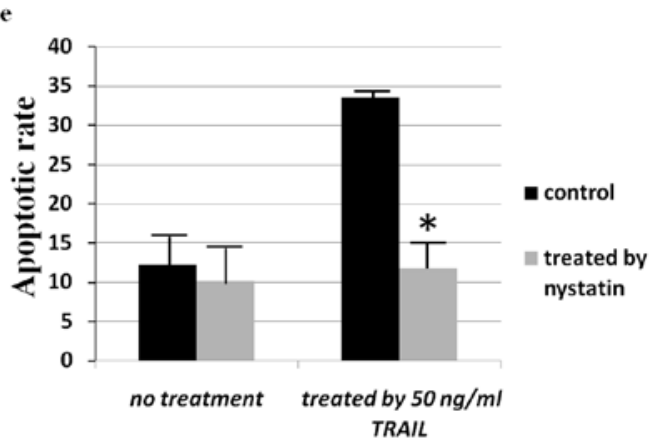

Figure 5. The protein expression of DR4, DR5, caspase-8 in lipid raft and non-raft fractions. (a) A549 cells with or without 50 ng/ml TRAIL treatment was subjected to ultracentrifugation onto a linear sucrose gradient and cell fractions were isolated. Arabic numerals represent fractions of $1 \mathrm{ml}$ collected from the top to the bottom of the gradient. The protein expression of DR4, DR5, caspase-8 in lipid rafts and non-raft fractions was analyzed by Western blotting; (b) H460 cells with or without $50 \mathrm{ng} / \mathrm{ml}$ TRAIL treatment was subjected to ultracentrifugation onto a linear sucrose gradient and cell fractions were isolated. Arabic numerals represent fractions of $1 \mathrm{ml}$ collected from the top to the bottom of the gradient. The protein expression of DR4, DR5, caspase-8 in lipid raft and non-lipid raft fractions was analyzed by Western blotting; Caveolin-1 is a marker of lipid rafts; (c) H460 cells with or without $50 \mathrm{ng} / \mathrm{ml}$ TRAIL pretreatment, was treated with $20 \mathrm{ng} / \mathrm{ml}$ nystatin for the last $12 \mathrm{~h}$, then subjected to ultracentrifugation onto a linear sucrose gradient and cell fractions were isolated, Arabic numerals represent fractions of $1 \mathrm{ml}$ collected from the top to the bottom of the gradient. The protein expression of DR4, DR5, caspase-8 in fractions was analyzed by Western blotting; (d) The apotosis of H460 cells with $20 \mathrm{ng} / \mathrm{ml}$ nystatin and/or $50 \mathrm{ng} / \mathrm{ml}$ TRAIL treatment was analyzed by flow cytometry; (e) A graphic representation of the mean data presented in (d). ${ }^{*} \mathrm{P}<0.05$ compared with control. Columns represent the mean data.

indicate that it is the TRAIL-induced redistribution, not initial distribution of DR4 and DR5 in lipid rafts on membrane surface, that contributed to the sensitivity to TRAIL-induced apoptosis in two NSCLC cell lines, which conforms to our conclusion.

\section{Discussion}

The selective toxicity of TRAIL against cancer cells makes it an attractive candidate for treating cancers (31). In fact, a recombinant, soluble form of TRAIL and monoclonal anti- 
bodies against its death receptors have been developed and used in clinical trials (32-35). Several lines of evidence suggest that TRAIL could serve as a therapeutic agent in the treatment of NSCLC, a tumor with limited prognosis. However, analysis of a large panel of established human NSCLC cell lines shows that the majority of NSCLC cells were either partially or completely resistant to TRAIL (27). TRAIL-induced apoptosis occurs when DR4 and/or DR5 trimerizes, the DISC forms, and caspases are activated. As a result, the lack of expression of DR4 and DR5 on the surface of some cancer cells is a resistance mechanism (36) regardless of total DR4 and DR5 protein levels. Because their absence on cell surface is sufficient to account for the failure in forming DISC and later events of apoptosis. Loss of cell surface expression of death receptors may be evaluated as a predictive biomarker for TRAIL-resistance in lung cancer cells. However, our results showed that there was no correlation between TRAIL-sensitivity of lung cancer cells and the DR4/ DR5 total mRNA or total protein expression, even expression on cell surface (Fig. 2). In our study, TRAIL-sensitive H460 cell and TRAIL-resistant A549 cells expressed similar level of DR5, wheras A549 cell have higher expression level of DR4 (Fig. 2). These results suggest that death receptor expression on cell surface is necessary but not sufficient for TRAIL-induced apoptosis, even though death receptors expressed on cell surface are considered as functional receptors. In this study, we did not detect the expression of decoy receptors (DcR1 and DcR2), since many reports indicated that the expression of decoy receptors did not correlate with resistance to TRAIL of cancer cell lines $(27,37,38)$ Due to the fact that some experts consider DR5 was the main transducer of the death signal for TRAIL compared with DR4 $(38,39)$, in order to investigate whether higher expression of DR4 in A549 competitive with DR5 binding to TRAIL results in resistance to TRAIL, A549 cells were transfected with DR4 siRNA, the expression of DR4 was restrained (Fig. 3a and b), but its apoptosis induced by TRAIL showed no change (Fig. 3d and e). These results indicate that the TRAIL-resistance of A549 is not related with DR4 competitive binding to TRAIL.

Our results offer new insights into the mechanism of resistance to TRAIL in NSCLC cell lines. It is reported that DR4 and DR5 would migrate to the membrane surface in the presence of TRAIL $(28,38)$, whereas other results suggested that DR4 and DR5 would undergo internalization in JBAB Burkitt lymphoma B-cell line and breast cancer cell lines after TRAIL treatment $(29,40,41)$. In our study, it seems that TRAIL downregulates surface expression of its death receptors DR4 and DR5 in A549 and H460 cells by directly detecting DR4 and DR5 (Fig. 4a and b), but the amount of TRAIL binding to death receptors increase in a time-dependent manner in TRAIL-sensitive H460 cells with TRAIL pretreatment, whereas the binding of TRAIL in A549 cells is very slight (Fig. 4c). The formation of TRAIL immunocomplexes indirectly reflects the amount of death receptors distributed on the cell surface, so TRAILsensitive lung cells showed more death receptor aggregates on the membrane surface than TRAIL-resistant lung cells. The results above seem to be contradictory. A rational explanation for the two contradictory phenomena is that DR4 and DR5 would be unavailable to its respective primary antibody after TRAIL pretreatment, the fluorescence intensity detected is the amount of DR4/DR5 unbinding to TRAIL, but not the total amount of DR4/DR5 on the membrane surface of lung cancer cells. The result indicates that TRAIL is able to promote DR4 and DR5 migration into plasma membrane only in sensitive H460 cell not resistant A549 cells. Thus, it can be seen that TRAIL is not capable of promoting death receptor aggeration in every cell line. From the results, we can speculate that there might be correlation between TRAIL-induced migration and TRAIL-induced apoptosis. The following results will further confirm our speculation.

Lipid rafts play an important role in clustering or aggregating surface receptors, signaling enzymes and adaptor molecules into membrane complexes at specific sites and are essential for initiating signaling from several receptors. Several models for signal initiation in rafts have been proposed $(42,43)$. Caveolin-1 is a lipid maker that is present in lipid rafts (25). Our results identified fractions 4 and 5 as lipid rafts (Fig. 5a and b). Without TRAIL pretreatment, the distribution of DR4, DR5 and caspase-8 in lipid fractions in H460 and A549 cell were almost similar, which revealed that the initial distribution of death receptors and caspase- 8 is not related with TRAILsensitivity; however, with TRAIL pretreatment, the migration of DR4, DR5 and caspase-8 into lipid rafts only occurred in H460 not A549 cells. Consequently, TRAIL could not increase the total mRNA or protein expression of death receptors but could induce a redistribution into the raft domains on the plasma membrane of TRAIL-sensitive H460 cells (Fig. 5b). It comfirmed that the migration of DR4/DR5 into lipid rafts in membrane surface induced by TRAIL contributed to the sensitization to apoptosis. TRAIL treatment also leads to the redistribution of the components of DISC, such as caspase-8, from non-rafts to lipid rafts, which may promote the assembly of DISC in lipid rafts. Nystatin is a cholesterol-sequestering agent, that is supposed to restrain membrane protein migration into lipid rafts $(42,43)$. We further examined the condition of DR4, DR5 and casepase- 8 redistribution and apotosis level of H460 with nystatin intervention. Under $20 \mathrm{ng} / \mathrm{ml}$ nystatin treatment, TRAIL could not induce DR4, DR5 and caspase-8 to migrate into lipid rafts (Fig. 5c), and the TRAIL-induced apotosis decreased (Fig. 5d and e). For the second time, the results confirmed it was the TRAIL-induced redistribution, not initial distribution of DR4 and DR5 in lipid rafts of membrane surface, that contributed to the sensitivity to TRAIL-induced apoptosis in the two NSCLC cell lines.

As death receptors, DR4 and DR5 must be properly expressed on cell surface to recruit the components of DISC into lipid rafts, then transmit an apoptotic signal from their ligands. Agents or interventions that upregulate the amout of death receptors in lipid rafts on cell surface could sensitize cell to TRAIL, such as oxaliplatin (44), resveratrol (25), depsipeptide (28), and irradiation (21). The molecular mechanism for TRAIL-induced redistribution of death receptors in lipid rafts remains unclear, but it may involve the protein sorting machinery. Recent studies suggest that protein transport and endocytosis pathways may play an important role in the regulation of surface death receptor expression $(19,41,45)$. Additional studies are required to characterize the signaling pathways that are responsible for TRAIL-induced redistribution of its death receptors and caspase- 8 .

Taken together, TRAIL is a promising therapeutic agent that induces apoptosis selectively in cancer cells. TRAIL has 
shown limited efficiency in the treatment of several NSCLC cells because of intrinsic or acquired resistance. So it is very important to investigate the molecular mechanisms of TRAIL-resistant in NSCLC cells. Here, we confirmed that TRAIL could induce redistribution of death receptors DR4/ DR5, together with caspase- 8 in lipid rafts. Consequently, comparing with properties of two different TRAIL-sensitive NSCLC cell lines, we conclude the TRAIL-induced migration of DR4/DR5 and caspase- 8 into lipid rafts and the assembly of DISC in lipid rafts contributed to the sensitivity to TRAIL. Other mechanisms along the apoptotic pathway might simultaneously exist, also resulting in TRAIL-resistance in A549 cells, which needs further exploration. This study indicates that targeting of the molecular modulation of the death receptor redistribution in lipid rafts may provide novel therapeutic strategies in overcoming TRAIL-resistance, and thus provides an effective therapeutic approach in TRAIL-based combination treatments of NSCLC and possibly other human cancers.

\section{Acknowledgements}

This study was supported by grants from National Natural Science Foundation of China (no. 81071908) and PhD Student Independent Scientific Research Program of Wuhan University (no. 20103030201000214).

\section{References}

1. Ichikawa K, Liu W, Zhao L, Wang Z, Liu D, Ohtsuka T, Zhang H, Mountz JD, Koopman WJ, Kimberly RP and Zhou T: Tumoricidal activity of a novel anti-human DR5 monoclonal antibody without hepatocyte cytotoxicity. Nat Med 7: 954-960, 2001

2. Hao C, Song JH, Hsi B, Lewis J, Song DK, Petruk KC, Tyrrell DL and Kneteman NM: TRAIL inhibits tumor growth but is nontoxic to human hepatocytes in chimeric mice. Cancer Res 64 8502-8506, 2004.

3. LeBlanc HN and Ashkenazi A: Apo2L/TRAIL and its death and decoy receptors. Cell Death Differ 10: 66-75, 2003.

4. Takeda K, Stagg J, Yagita H, Okumura K and Smyth MJ: Targeting death-inducing receptors in cancer therapy. Oncogene 26: 3745-3757, 2007

5. Yagita H, Takeda K, Hayakawa Y, Smyth MJ and Okumura K: TRAIL and its receptors as targets for cancer therapy. Cancer Sci 95: 777-783, 2004

6. Bhojani MS, Rossu BD and Rehemtulla A: TRAIL and antitumor responses. Cancer Biol Ther 2: S71-S78, 2003.

7. Wiley SR, Schooley K, Smolak PJ, Din WS, Huang CP, Nicholl JK, Sutherland GR, Smith TD, Rauch C, Smith CA, et al: Identification and characterization of a new member of the TNF family that induces apoptosis. Immunity 3: 673-682, 1995.

8. Pitti RM, Marsters SA, Ruppert S, Donahue CJ, Moore A and Ashkenazi A: Induction of apoptosis by Apo-2 ligand, a new member of the tumor necrosis factor cytokine family. J Biol Chem 271: 12687-12690, 1996.

9. Smyth MJ, Takeda K, Hayakawa Y, Peschon JJ, van den Brink MR and Yagita H: Nature's TRAIL-on a path to cancer immunotherapy. Immunity 18: 1-6, 2003.

10. Thomas WD and Hersey P: TNF-related apoptosis-inducing ligand (TRAIL) induces apoptosis in Fas ligand-resistant melanoma cells and mediates CD4 T cell killing of target cells. J Immunol 161: 2195-2200, 1998.

11. Pan G, O'Rourke K, Chinnaiyan AM, Gentz R, Ebner R, Ni J and Dixit VM: The receptor for the cytotoxic ligand TRAIL. Science 276: 111-113, 1997.

12. Pan G, Ni J, Wei YF, Yu G, Gentz R and Dixit VM: An antagonist decoy receptor and a death domain-containing receptor for TRAIL. Science 277: 815-818, 1997.

13. Johnstone RW, Frew AJ and Smyth MJ: The TRAIL apoptotic pathway in cancer onset, progression and therapy. Nat Rev Cancer 8: 782-798, 2008.
14. Luo X, Budihardjo I, Zou H, Slaughter C and Wang X: Bid, a $\mathrm{Bcl} 2$ interacting protein, mediates cytochrome $\mathrm{c}$ release from mitochondria in response to activation of cell surface death receptors. Cell 94: 481-490, 1998.

15. Griffith TS, Chin WA, Jackson GC, Lynch DH and Kubin MZ: Intracellular regulation of TRAIL-induced apoptosis in human melanoma cells. J Immunol 161: 2833-2840, 1998.

16. Sheridan JP, Marsters SA, Pitti RM, Gurney A, Skubatch M, Baldwin D, Ramakrishnan L, Gray CL, Baker K, Wood WI, Goddard AD, Godowski P and Ashkenazi A: Control of TRAILinduced apoptosis by a family of signaling and decoy receptors. Science 277: 818-821, 1997.

17. Zhang XD, Nguyen T, Thomas WD, Sanders JE and Hersey P: Mechanisms of resistance of normal cells to TRAIL induced apoptosis vary between different cell types. FEBS Lett 482: 193-199, 2000.

18. Wagner KW, Punnoose EA, Januario T, Lawrence DA, Pitti RM, Lancaster K, Lee D, von Goetz M, Yee SF, Totpal K, Huw L, Katta V, Cavet G, Hymowitz SG, Amler L and Ashkenazi A: Death-receptor O-glycosylation controls tumor-cell sensitivity to the proapoptotic ligand Apo2L/TRAIL. Nat Med 13: 1070-1077, 2007.

19. Jin Z, McDonald ER 3rd, Dicker DT and El-Deiry WS: Deficient tumor necrosis factor-related apoptosis-inducing ligand (TRAIL) death receptor transport to the cell surface in human colon cancer cells selected for resistance to TRAIL-induced apoptosis. J Biol Chem 279: 35829-35839, 2004.

20. Cheng J, Hylander BL, Baer MR, Chen X and Repasky EA: Multiple mechanisms underlie resistance of leukemia cells to Apo2 Ligand/TRAIL. Mol Cancer Ther 5: 1844-1853, 2006.

21. Wu F, Hu Y, Long J, Zhou YJ, Zhong YH, Liao ZK, Liu SQ, Zhou FX, Zhou YF and Xie CH: Cytotoxicity and radiosensitization effect of TRA-8 on radioresistant human larynx squamous carcinoma cells. Oncol Rep 21: 461-465, 2009.

22. Hu Y, Ouyang W, Wu F, Cao CH, Wang K, Liao ZK, Zhong YH, Zhou FX, Liu SQ, Xia L, Zhou YF and Xie CH: Enhanced radiosensitivity of SW480 cells via TRAIL up-regulation mediated by Egr-1 promoter. Oncol Rep 22: 765-771, 2009.

23. Muppidi JR, Tschopp J and Siegel RM: Life and death decisions: secondary complexes and lipid rafts in TNF receptor family signal transduction. Immunity 21: 461-465, 2004.

24. Psahoulia FH, Drosopoulos KG, Doubravska L, Andera L and Pintzas A: Quercetin enhances TRAIL-mediated apoptosis in colon cancer cells by inducing the accumulation of death receptors in lipid rafts. Mol Cancer Ther 6: 2591-2599, 2007.

25. Delmas D, Rebe C, Micheau O, Athias A, Gambert P, Grazide S, Laurent G, Latruffe N and Solary E: Redistribution of CD95, DR4 and DR5 in rafts accounts for the synergistic toxicity of resveratrol and death receptor ligands in colon carcinoma cells. Oncogene 23: 8979-8986, 2004.

26. Simons K and Vaz WL: Model systems, lipid rafts, and cell membranes. Annu Rev Biophys Biomol Struct 33: 269-295, 2004

27. Song JH, Tse MC, Bellail A, Phuphanich S, Khuri F, Kneteman NM and Hao C: Lipid rafts and nonrafts mediate tumor necrosis factor related apoptosis-inducing ligand induced apoptotic and nonapoptotic signals in non small cell lung carcinoma cells. Cancer Res 67: 6946-6955, 2007.

28. Vanoosten RL, Moore JM, Ludwig AT and Griffith TS: Depsipeptide (FR901228) enhances the cytotoxic activity of TRAIL by redistributing TRAIL receptor to membrane lipid rafts. Mol Ther 11: 542-552, 2005.

29. Kohlhaas SL, Craxton A, Sun XM, Pinkoski MJ and Cohen GM: Receptor-mediated endocytosis is not required for tumor necrosis factor-related apoptosis-inducing ligand (TRAIL)-induced apoptosis. J Biol Chem 282: 12831-12841, 2007.

30. Jin H, Yang R, Fong S, Totpal K, Lawrence D, Zheng Z, Ross J, Koeppen H, Schwall R and Ashkenazi A: Apo2 ligand/tumor necrosis factor-related apoptosis-inducing ligand cooperates with chemotherapy to inhibit orthotopic lung tumor growth and improve survival. Cancer Res 64: 4900-4905, 2004.

31. Kelley SK and Ashkenazi A: Targeting death receptors in cancer with Apo2L/TRAIL. Curr Opin Pharmacol 4: 333-339, 2004.

32. Peter ME: Taming TRAIL: the winding path to a novel form of cancer therapy. Cell Death Differ 12: 693-694, 2005.

33. Greco FA, Bonomi P, Crawford J, Kelly K, Oh Y, Halpern W, Lo L, Gallant G and Klein J: Phase 2 study of mapatumumab, a fully human agonistic monoclonal antibody which targets and activates the TRAIL receptor-1, in patients with advanced non-small cell lung cancer. Lung Cancer 61: 82-90, 2008. 
34. Smith MA, Morton CL, Kolb EA, Gorlick R, Keir ST, Carol H Lock R, Kang MH, Reynolds CP, Maris JM, Watkins AE and Houghton PJ: Initial testing (stage 1) of mapatumumab (HGSETR1) by the pediatric preclinical testing program. Pediatr Blood Cancer 54: 307-310, 2010.

35. Wakelee HA, Patnaik A, Sikic BI, Mita M, Fox NL, Miceli R, Ullrich SJ, Fisher GA and Tolcher AW: Phase I and pharmacokinetic study of lexatumumab (HGS-ETR2) given every 2 weeks in patients with advanced solid tumors. Ann Oncol 21: 376-381, 2010.

36. Horak P, Pils D, Haller G, Pribill I, Roessler M, Tomek S, Horvat R, Zeillinger R, Zielinski C and Krainer M: Contribution of epigenetic silencing of tumor necrosis factor-related apoptosis inducing ligand receptor 1 (DR4) to TRAIL resistance and ovarian cancer. Mol Cancer Res 3: 335-343, 2005.

37. Zhang Y and Zhang B: TRAIL resistance of breast cancer cells is associated with constitutive endocytosis of death receptors 4 and 5. Mol Cancer Res 6: 1861-1871, 2008

38. Gomez-Benito M, Martinez-Lorenzo MJ, Anel A, Marzo I and Naval J: Membrane expression of DR4, DR5 and caspase- 8 levels, but not Mcl-1, determine sensitivity of human myeloma cells to Apo2L/TRAIL. Exp Cell Res 313: 2378-2388, 2007.

39. Huang Y and Sheikh MS: TRAIL death receptors and cancer therapeutics. Toxicol Appl Pharmacol 224: 284-289, 2007.
40. Zhang Y, Yoshida T and Zhang B: TRAIL induces endocytosis of its death receptors in MDA-MB-231 breast cancer cells. Cancer Biol Ther 8: 917-922, 2009.

41. Austin CD, Lawrence DA, Peden AA, Varfolomeev EE, Totpal K, De Maziere AM, Klumperman J, Arnott D, Pham V, Scheller RH and Ashkenazi A: Death-receptor activation halts clathrin-dependent endocytosis. Proc Natl Acad Sci USA 103: 10283-10288, 2006.

42. Simons K and Toomre D: Lipid rafts and signal transduction. Nat Rev Mol Cell Biol 1: 31-39, 2000.

43. Dimanche-Boitrel MT, Meurette O, Rebillard A and Lacour S: Role of early plasma membrane events in chemotherapy-induced cell death. Drug Resist Updat 8: 5-14, 2005.

44. Xu L, Qu X, Zhang Y, Hu X, Yang X, Hou K, Teng Y, Zhang J, Sada K and Liu Y: Oxaliplatin enhances TRAIL-induced apoptosis in gastric cancer cells by CBL-regulated death receptor redistribution in lipid rafts. FEBS Lett 583: 943-948, 2009.

45. Ren YG, Wagner KW, Knee DA, Aza-Blanc P, Nasoff M and Deveraux QL: Differential regulation of the TRAIL death receptors DR4 and DR5 by the signal recognition particle. Mol Biol Cell 15: 5064-5074, 2004. 